\title{
BMJ Open Pregnancy outcomes in Lebanese women with multiple sclerosis (the LeMS study): a prospective multicentre study
}

\author{
Jawad Fares, ${ }^{1,2}$ Anwar H Nassar, ${ }^{3}$ Souheil Gebeily, ${ }^{1,4}$ Firas Kobeissy, ${ }^{5,6}$ \\ Youssef Fares ${ }^{1,7}$
}

To cite: Fares J, Nassar AH, Gebeily S, et al. Pregnancy outcomes in Lebanese women with multiple sclerosis (the LeMS study): a prospective multicentre study. BMJ Open 2016;6:e011210. doi:10.1136/bmjopen-2016011210

- Prepublication history for this paper is available online. To view these files please visit the journal online (http://dx.doi.org/10.1136/ bmjopen-2016-011210).

Received 20 January 2016 Revised 22 February 2016 Accepted 20 April 2016

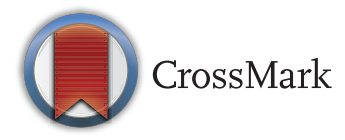

For numbered affiliations see end of article.

Correspondence to Professor Youssef Fares; yfares@ul.edu.Ib

\section{ABSTRACT}

Objective: The Lebanese Multiple Sclerosis (LeMS) study aims to assess the influence of pregnancy and delivery on the clinical course of multiple sclerosis (MS) in Lebanese women.

Setting: This prospective multicentre study took place in three MS referral university medical centres in Lebanon.

Participants: Included were 29 women over 18 years who had been diagnosed with MS according to the McDonald criteria, and became pregnant between 1995 and 2015. Participating women should have stopped treatment 3 months before conception and become pregnant after the onset of MS. Women were followed up from 1 year preconceptionally and for 4 years postpartum.

Main outcome measures: The annualised relapse rates per participant during each 3-month period during pregnancy and each year postpartum were compared with the relapse rate during the year before pregnancy using the paired two-tailed $t$ test. $p$ Values $<0.05$ were considered statistically significant for all analyses $(95 \% \mathrm{Cl})$.

Results: 64 full-term pregnancies were recorded. All pregnancies $(100 \%)$ resulted in live births, with no complications or other diseases. In comparison with the prepregnancy year, in which the mean relapse rate \pm SE was $0.17 \pm 0.07$, there was a significant reduction in the relapse rate during pregnancy and in the first year postpartum $(p=0.02)$, but an increase in the rate in the second year postpartum $(0.21 \pm 0.08)$. Thereafter, from the third year postpartum through the following fourth year, the annualised relapse rate fell slightly but did not differ from the annualised relapse rate recorded in the prepregnancy year $(0.17 \pm 0.07)$.

Conclusions: Pregnancy in Lebanese women with MS does not seem to increase the risk of complications. No relapses were observed during pregnancy and in the first year postpartum; however, relapses rebounded in the second year postpartum, and over the long term, returned to the levels that preceded pregnancy.

\section{Strengths and limitations of this study}

- This is the first study to analyse pregnancy related issues in patients with multiple sclerosis (MS) that has been conducted in Lebanon and the Middle East and North Africa region.

- All women were primiparous, had planned for the pregnancies, had stopped treatment 3 months before conception, did not smoke or drink alcohol or use drugs, reported no pregnancy or delivery complications, no birth defects or diseases postpartum, and were capable of breastfeeding.

- The women served as their own controls because matching a cohort of pregnant women with MS with a cohort of women with MS who did not become pregnant would have been difficult.

- The LeMS study is unique in the sense that it was the first to demonstrate that relapses disappeared completely during pregnancy and in the first year postpartum.

- The sample size of our study may have contributed to the lack of significant differences in some of the outcomes.

\section{INTRODUCTION}

Multiple sclerosis (MS) is a chronic autoimmune disease of the central nervous system. Individuals diagnosed with MS are usually young women of childbearing age. ${ }^{1}$ Therefore, pregnancy-related issues, including childbirth and neonatal health, have become a concern for MS professionals and patients. Until the end of the 20th century, women with MS were discouraged from contemplating pregnancy due to the false belief that pregnancy would worsen the overall disease course. $^{2-7}$ Furthermore, concerns about the progression of neurological disability over time affected family planning 
choices. ${ }^{8}$ Women with MS were naturally fretful as to how pregnancy would affect their disease, how the disease might modify pregnancy outcomes, and in particular, how the disease or the medications they were taking could affect the fetus. ${ }^{9}$ As a result of the 1998 publication of the first large prospective study of pregnancy and $\mathrm{MS},{ }^{10}$ family planning and counselling recommendations for women with MS radically changed, and many women have been able to fulfil their desire for motherhood. During this same time period, treatment options for MS accelerated and several disease-modifying drugs for MS entered the market. ${ }^{9}$

The cause of MS is unknown, but susceptibility to the disease is believed to be co-influenced by genetic and environmental factors. ${ }^{1}$ The risk of MS in children with one parent with MS is $1-3 \%,{ }^{11}$ and $6-12 \%$ for children whose both parents have MS. ${ }^{12}{ }^{13}$ However, the overall risk remains low, and having MS should not discourage patients with MS from having a child.

Until now, no studies analysing pregnancy and birth outcomes in women with MS have been carried out in Lebanon or in the Middle East and North Africa (MENA) region; the evolution of MS during pregnancy in the MENA region is largely unknown. Therefore, the objective of the Lebanese multiple sclerosis (LeMS) study is to explore pregnancy, labour and delivery course, and the birth outcomes in Lebanese women with MS.

\section{METHODS}

\section{Study design}

This was a prospective multicentre study of women from three MS referral centres in Lebanon. Information on women diagnosed with definite MS who became pregnant after the onset of the disease between 1995 and 2015 was collected through interviews. All women gave informed consent after they agreed to participate in the study.

\section{Participants}

Women aged over 18 years were recruited in the study. To be included, women had to have clinically diagnosed definite MS according to the 2010 McDonald criteria, clinical and para-clinical tests, and quantitative or qualitative abnormalities in immunoglobulins in the cerebrospinal fluid (CSF). In addition, they had to have become pregnant after the onset of MS. The 2010 McDonald criteria allowed for a more rapid diagnosis of MS, with equivalent or improved specificity and/or sensitivity compared with the past criteria. ${ }^{14}$ It also clarified and simplified the diagnostic process with fewer required MRI. Only women who were deemed mentally competent were eligible for participation in the study.

\section{Assessment}

Before pregnancy, each new relapse-defined as showing a neurological dysfunction lasting longer than
$24 \mathrm{~h}$-was recorded and confirmed by a neurological examination. Treatment was prescribed if the relapse caused disability. During pregnancy, women were seen by a neurological specialist at 9-12 weeks and 2629 weeks of gestation, and at 4-6 weeks and 10-12 weeks postpartum; these women were later followed for up to 4 years. Information on neurological conditions was collected by interviewing the women at each visit, and by telephone in case of any neurological event; obstetrical data were obtained by interviewing the women and reviewing the medical record. In-person interviews were used in this study despite the limitation of requiring a person to conduct the interview because these provide an opportunity for clarifying questions the woman could not otherwise understand.

\section{Demographic and outcome measures}

The data collected were as follows: (1) demographic and MS-related variables: age at MS onset; level of education; marital status; type of MS (relapsing-remitting MS (RRMS), secondary progressive MS, primary progressive MS, and progressive-relapsing MS); and mean annualised relapse rate before, during, and after pregnancy (calculated as the ratio between the number of relapses experienced by each woman and the number of years for each period); (2) pregnancy-related variables: age during pregnancy; number of pregnancies after the onset of MS; history of smoking, alcohol, and drug use during pregnancy; history of relapses before, during, and after pregnancy; treatment before, during and after pregnancy; vitamin D3, magnesium, antidepressant and co-enzyme Q-10 supplementation; gestational diabetes mellitus (GDM); infections; preeclampsia; and preterm and post-term infants; (3) delivery-related variables: induction of labour, instrumental delivery, epidural and general anaesthesia, frequency of caesarean sections and normal vaginal deliveries; and (4) infant-related variables: mean gestational age, mean birth weight, low birth weight status, high birth weight status, birth defects or other diseases; and history of breastfeeding.

\section{Statistical analysis}

The relapse rates for each woman during each trimester of pregnancy and the 3 years postpartum were compared with the relapse rate during the year before pregnancy by means of paired two-tailed t tests. The paired $t$ test was used as it calculates the difference within each before-and-after pair of measurements, determines the mean of these changes and reports whether this mean of differences is statistically significant. The effects of other demographic, pregnancy and infant-related variables on the course of MS were analysed using logistic regression, as these were thought to be associated with the presence or absence of a relapse in the postpartum phase. $p$ Values $<0.05$ were considered statistically significant for all analyses (95\% CI). All statistical analyses were performed with SPSS for Windows software V.23 (IBM SPSS, 2015). 


\section{RESULTS}

There were 29 women with definite MS who met the inclusion criteria. All of them agreed to participate in the study. We identified 64 pregnancies that had occurred since MS onset.

\section{Demographic and MS characteristics}

The mean age $\pm \mathrm{SD}$ of MS onset was $23 \pm 3.4$ years (range= (16-34)). All (100\%) had RRMS. Diagnosis was made using the 2010 McDonald criteria, MRI, and CSF studies. A total of 21 women $(72.4 \%)$ were married and presenting for pregnancy consultation, and 8 (27.6\%) were engaged to be married and were receiving consultation on the potential for starting a family. The complete profile of the women is displayed in table 1 .

\begin{tabular}{|c|c|}
\hline Variables & $\mathbf{N}(\%)$ \\
\hline \multicolumn{2}{|l|}{ Age (years) } \\
\hline Mean age at MS onset & 23 years \\
\hline Mean age at pregnancy onset & 26.6 years \\
\hline \multicolumn{2}{|l|}{ Level of education } \\
\hline High school & $21(72.4)$ \\
\hline Undergraduate & $8(27.6)$ \\
\hline \multicolumn{2}{|l|}{ Marital status } \\
\hline Engaged & $8(27.6)$ \\
\hline Married & $21(72.4)$ \\
\hline \multicolumn{2}{|l|}{ Comorbidities } \\
\hline Diabetes & $2(6.9)$ \\
\hline Hypertension & $3(10.3)$ \\
\hline \multicolumn{2}{|l|}{ MS lesions } \\
\hline Brain & $29(100)$ \\
\hline Brain and cervical spine & $7(24.1)$ \\
\hline \multicolumn{2}{|l|}{ MS diagnosis } \\
\hline MRI & $29(100)$ \\
\hline CSF and oligoclonal positive & 26 (89.7) \\
\hline CSF and oligoclonal not performed & $3(10.3)$ \\
\hline \multicolumn{2}{|l|}{ Pregnancies after MS onset } \\
\hline One & $4(13.8)$ \\
\hline Two & $15(51.7)$ \\
\hline Three & $10(34.5)$ \\
\hline \multicolumn{2}{|l|}{ Supplements taken during pregnancy } \\
\hline Vitamin D3 & $21(72.4)$ \\
\hline Co-enzyme Q-10 & $20(69)$ \\
\hline Fluoxetine & $11(37.9)$ \\
\hline Magnesium sulfate & $21(72.4)$ \\
\hline \multicolumn{2}{|l|}{ Delivery method } \\
\hline Normal vaginal & $23(79.3)$ \\
\hline Caesarean & $6(20.7)$ \\
\hline Epidural anaesthesia & $21(72.4)$ \\
\hline \multicolumn{2}{|l|}{ Length of breastfeeding (days) } \\
\hline $21-35$ & $6(20.7)$ \\
\hline $93-255$ & $23(79.3)$ \\
\hline \multicolumn{2}{|l|}{ Treatment after pregnancy } \\
\hline Resumed after $11-14$ months & $22(75.9)$ \\
\hline Stopped indefinitely & 7 (24.1) \\
\hline
\end{tabular}

\section{Pregnancy characteristics}

Women had a mean age \pm SD of $26.6 \pm 3.8$ years during pregnancy $($ range $=(19-43))$. Four women $(13.8 \%)$ had one pregnancy after the onset of MS, $15(51.7 \%)$ had two, and $10(34.5 \%)$ had three pregnancies. All of these women $(100 \%)$ were primiparous when they agreed to participate in the study. All of the pregnancies (100\%) were planned pregnancies. None of the women smoked, drank alcohol or used drugs during pregnancy. Three pregnancies $(4.7 \%)$ occurred in women who had preGDM and another three pregnancies (4.7\%) occurred in women who had chronic hypertension. None of the women had reported urinary tract infections or any other infections during pregnancy. No ectopic pregnancies occurred. No cholecystitis, gestational diabetes or abortions occurred. No preeclampsia or placental disorders were reported. All of the pregnancies were full term. All pregnancies $(100 \%)$ resulted in live births. None of the women got pregnant in the 4 years postpartum. We found no evidence of an association between any of the pregnancy characteristics and other known risk factors.

\section{Treatment}

Before pregnancy, 23 women $(79.3 \%)$ were on intramuscular interferon $\beta-1 \mathrm{a}$ and received one injection per week. The other 6 women (20.7\%) were on subcutaneous interferon $\beta-1 \mathrm{a}$ and received three injections per week. The treatment modality differed by physician and patient preference. Treatment was stopped 3 months before conception for all women.

In 44 of 64 pregnancies $(68.6 \%)$, women took vitamin D3 and magnesium supplements (200 mg, once daily). In 41 pregnancies $(64.1 \%)$, the women took co-enzyme Q-10 supplements. Low dose of fluoxetine $(10 \mathrm{mg}$, once daily) was prescribed in 22 pregnancies $(34.4 \%)$.

Following delivery, the mother's condition was neurologically assessed, and the woman was asked to continue without treatment in order to breastfeed. After 1114 months, 22 women $(75.9 \%)$ resumed the treatment regimen that they were using in the prepregnancy phase. However, 7 women $(24.1 \%)$ decided on their own to stop treatment indefinitely; these women had 19 pregnancies $(29.7 \%)$ with no complications and were able to lead normal lives.

\section{MS relapses}

The annualised relapse rates in the years before, during, and after pregnancy are presented in table 2 and figure 1 . In comparison with the prepregnancy year, in which the mean \pm SE relapse rate was $0.17 \pm 0.07$, there was a significant reduction in the relapse rate during pregnancy and in the first year postpartum $(\mathrm{p}=0.02)$, but an increase in the relapse rate the second year after delivery $(0.21 \pm 0.08)$. Thereafter, from the third postpartum year through the following fourth year, the annualised relapse rate fell slightly but did not differ from the 
Table 2 Relapses of multiple sclerosis during pregnancy among 29 Lebanese women

\begin{tabular}{|c|c|c|c|c|}
\hline Period & Number of women* & Number of relapses & Rate of relapse/woman/yeart & p Value \\
\hline Year before pregnancy & 29 & 5 & $0.17(0.03$ to 0.32$)$ & - \\
\hline \multicolumn{5}{|l|}{ Pregnancy } \\
\hline First trimester & 29 & 0 & 0 & 0.02 \\
\hline Second trimester & 29 & 0 & 0 & 0.02 \\
\hline Third trimester & 29 & 0 & 0 & 0.02 \\
\hline \multicolumn{5}{|l|}{ Postpartum } \\
\hline First year & 29 & 0 & 0 & 0.02 \\
\hline Second year & 29 & 6 & $0.21(-0.12$ to 0.04$)$ & 0.32 \\
\hline Third year & 29 & 5 & $0.17(0.03$ to 0.32$)$ & - \\
\hline Fourth year & 29 & 5 & 0.17 (0.03 to 0.32$)$ & - \\
\hline
\end{tabular}

annualised relapse rate recorded in the prepregnancy year $(0.17 \pm 0.07)$.

Among the 29 women with 64 live births, none had relapses during pregnancy or in the first year postpartum. Six $(21 \%)$ had one relapse each in the second year postpartum. Five $(17 \%)$ had one relapse each in the third and fourth years postpartum, respectively. None of the patients required prophylactic relapse treatment after labour.

We did not find any evidence of an association between relapses before pregnancy and relapses during the second, third or fourth year of the postpartum period. We did not find evidence of any association of post-labour MS relapses with other potential risk factors (age, breastfeeding, MS onset and duration, treatment before pregnancy, epidural anaesthesia or any other factor).

\section{Delivery and characteristics of newborns}

There were 12 planned caesarean deliveries (18.8\%). Forceps and vacuum were not used in any of the cases.
Normal vaginal delivery was achieved in 52 pregnancies $(81.2 \%)$. Epidural anaesthesia was used in 35 of 52 normal vaginal deliveries $(67.3 \%)$, and in all of the 12 caesarean deliveries $(100 \%)$. General anaesthesia was not used in any of the cases. All 64 pregnancies resulted in live births with no malformations or congenital anomalies. The mean fullterm birth weight was $3200 \mathrm{~g}$ (ranging from 2000 to $4250 \mathrm{~g})$. There was only one newborn (1.6\%) who was small for gestational age $(<10$ th centile for gestational age).

\section{Breastfeeding}

All of the newborns $(100 \%)$ were breast-fed. The mean duration of breastfeeding was 157 days (ranging from 21 to 255 days). Forty-eight newborns (75\%) were breast-fed for a period ranging from 93 to 255 days. Sixteen newborns $(25 \%)$ were breast-fed for a period between 21 and 35 days.

\section{DISCUSSION}

This is the first study to analyse pregnancy-related issues in patients with MS conducted in Lebanon and the

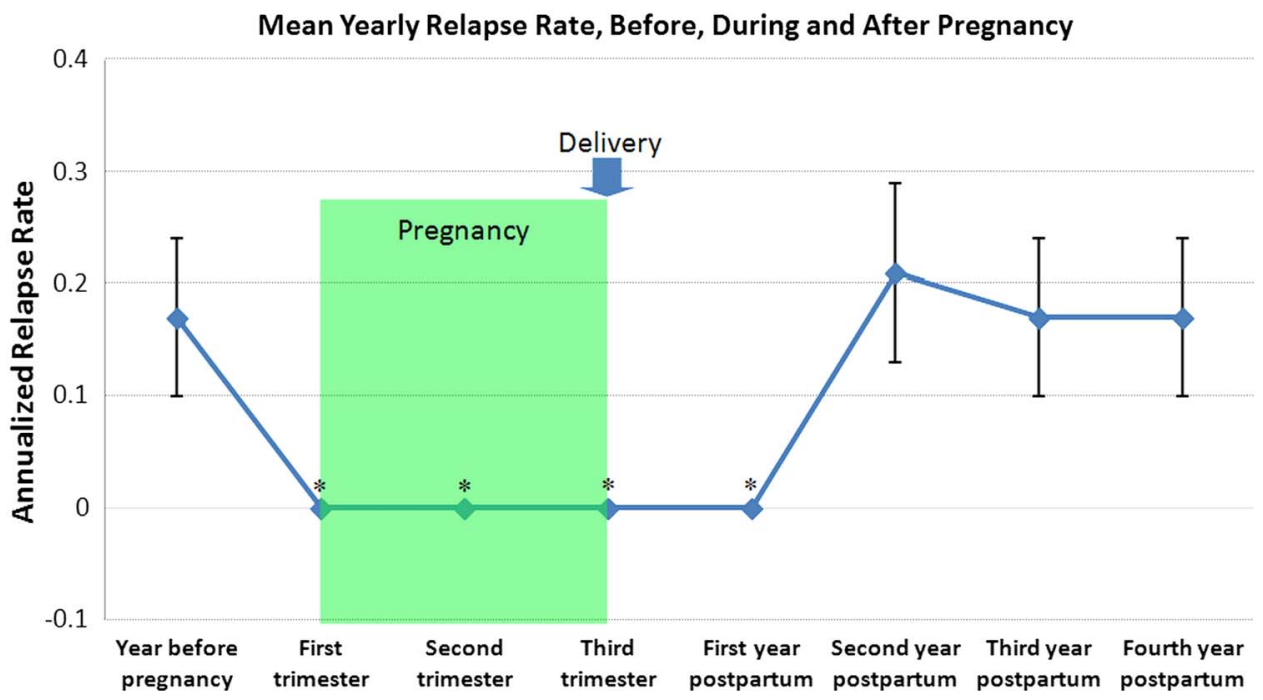

Figure 1 Annualised relapse rate in the year before pregnancy, during pregnancy, and in the four years after delivery among the 29 women with MS (vertical bars represent means and standard errors of means; * signifies $p<0.05$ for annualised relapse rate when compared to the year before pregnancy). MS, multiple sclerosis. 
MENA region. The frequency of relapses decreased significantly during pregnancy and in the first year postpartum compared with the rate estimated in the year before pregnancy. Relapse rates rebounded in the second year postpartum, and returned to the prepregnancy rate in the third and fourth years postpartum. In line with other studies in the literature, ${ }^{10}{ }^{15-19}$ all the women in our study had RRMS. However, our sample was unique in the sense that all women did not smoke, drink alcohol or use drugs. All women were primiparous, had planned for the pregnancies, had stopped treatment 3 months before conception, reported no pregnancy or delivery complications, had no birth defects or diseases postpartum and were capable of breastfeeding. Our study does not show any unfavourable pregnancy outcomes associated with MS.

\section{Comparison to similar studies}

Similar to other studies in the literature, ${ }^{10}{ }^{15-19}$ the relapse rate of MS decreased significantly during pregnancy. However, while other studies reported a significant decrease in relapse rates in the third trimester of pregnancy only, ${ }^{10}{ }^{15-18}$ our study reported a significant decrease in relapse rates in all three trimesters of pregnancy. Additionally, in contrast to studies showing that relapse rates rebounded significantly in the first trimester postpartum, ${ }^{10}{ }^{15-17}$ our study was the first to demonstrate a significant decrease in relapse rates in the first year postpartum and a non-significant rebound in the second year postpartum when compared to the prepregnancy rate. Similar to other studies, ${ }^{10} 15-172021$ over the long-term postpartum, the relapse rates eventually returned to prepregnancy rates.

The relapse rate in our study ranged between 0 and 0.21 , which is the lowest among all the previous similar studies. Confavreux et $a l^{10}$ reported relapse rates that ranged between 0.20 and 1.20 , Fernandez Liguori et $a l^{16}$ had relapse rates ranging between 0.04 and 0.82 , Jalkanen et $a l^{17}$ reported relapse rates that ranged between 0.40 and 1.40 , Salemi et $a l^{18}$ had relapse rates ranging between 0.36 and 0.72 , and Fragoso et $a l^{19}$ reported relapse rates that ranged between 0.29 and 1.37 .

Among women in this study, interferon $\beta$ 1-a treatment was stopped 3 months before conception as a precautionary measure to avoid pregnancy complications or birth defects. Fernandez Liguori $e t a l,{ }^{16}$ van Walderveen $e t a l^{21}$ and Sandberg-Wollheim et $a l^{22}$ reported that high doses of interferon $\beta$ increased spontaneous abortions and incidence of major birth defects (eg, Down syndrome, hydrocephalus, abnormalities in the $\mathrm{X}$ chromosome, etc). Several other studies suggest that, whenever possible, interferon $\beta$ treatment should be discontinued prior to conception. ${ }^{21-28}$ However, similar women in other studies continued to receive treatment modalities throughout pregnancy. ${ }^{10} 15-19$

Initially, vitamin D was given as a supplement to address the paucity women may suffer from during pregnancy, ${ }^{29}$ and to attend to the vitamin D deficiency in the general Lebanese population. ${ }^{30}$ More recent studies have also shown that maintaining adequate levels of vitamin $\mathrm{D}$ during pregnancy might have a protective effect and lower the risk of developing postpartum relapses. ${ }^{31}$

Psychological support was crucial in maintaining the mental well-being of the mother. ${ }^{32}$ Some women exhibited signs of anxiety and depression. Thus, after weighing risks and benefits, they were given fluoxetine in low doses to improve their mental health. Magnesium sulfate was also supplemented to support the pregnancy, avoid potential complications, and further improve the mental well-being of the women. ${ }^{33}$ Co-enzyme Q-10 was given to enhance fertility and egg quality. ${ }^{34-36}$

According to our study, MS does not seem to increase the risk of a caesarean delivery or require the use of instrumentation. In contrast, Dahl et $a \hat{l}^{7}$ and Jalkanen et $a l^{17}$ reported a high level of planned caesarean deliveries and instrumental deliveries in patients with MS. In line with previous studies, ${ }^{10} 1538$ epidural anaesthesia was not associated with an increase in postpartum relapses.

Most similar studies reported complications during and after pregnancy. ${ }^{10}{ }^{15-19}$ Our study, however, reported no obstetric complications; all of the pregnancies were full term and resulted in live births.

As all of the women in our sample breast-fed their babies, we did not find a significant relationship between the number of days spent breastfeeding and relapse. Similarly, other studies have also not found a significant association between breastfeeding and relapses. ${ }^{39-41}$ In practice, however, strong evidence supports the statement that breastfeeding does not increase the risk of postpartum relapse-it could even be protective. $^{4142}$ Confavreux $e t a l^{10}$ reported that women who chose to breastfeed experienced significantly fewer relapses and had milder disability scores in the year after pregnancy in comparison with women who chose not to breastfeed. As medications used for the treatment of MS may enter breast milk, these were normally withheld during breastfeeding. The decision of whether to resume a treatment postpartum was weighed against the potential benefits of breastfeeding.

\section{Strengths and limitations}

Careful prospective follow-up of women ensured good data quality and up-to-date information in the present study. The women served as their own controls because matching a cohort of pregnant women with MS with a cohort of women with MS who did not become pregnant would have been difficult. Our results are also in accordance with studies that have shown that MS does not seem to have a deleterious effect on the course and outcome of pregnancy or delivery. ${ }^{10}{ }^{15-19}$ Furthermore, the LeMS study is unique in the sense that it was the first to demonstrate that relapses disappeared completely during pregnancy and in the first year 
postpartum. Conversely, the sample size of our study may have contributed to the lack of significant differences in some of the outcomes.

\section{Future research}

A better understanding of the biological mechanisms underlying this pregnancy-related decrease in disease activity could lead to new and effective therapeutic strategies in MS. The reasons for the decreased relapse activity during pregnancy are not entirely clear, but factors such as increased oestrogen levels before delivery, and the immunosuppressive state of the women during pregnancy are likely to be of importance. ${ }^{43-45}$ The role of breastfeeding and its potential effect on relapses postpartum can also be explored; we hypothesise that high levels of prolactin in women with MS postpartum who are breastfeeding play a protective role. We also believe that the women's genetics, lifestyle, mental well-being, high vitamin D3, co-enzyme Q-10, and magnesium sulfate supplementations may generate a protective effect against relapses.

\section{Conclusions and implications}

In line with the previous conception studies, pregnancies in Lebanese women with MS do not seem to pose a risk of complications. No relapses were observed during pregnancy and in the first year postpartum; however, relapses rebounded in the second year postpartum, and over the long term, returned to the levels that preceded pregnancy. The characteristics and lifestyle of the women in the study can serve as a model to other women with MS who seek motherhood. Furthermore, the medical management presented in the LeMS study can be a guide to physicians in their future dealings with similar cases.

\section{Author affiliations}

${ }^{1}$ Neuroscience Research Center, Faculty of Medical Sciences, Lebanese University, Beirut, Lebanon

${ }^{2}$ Faculty of Medicine, American University of Beirut, Beirut, Lebanon ${ }^{3}$ Department of Obstetrics and Gynecology, American University of Beirut Medical Center, Beirut, Lebanon

${ }^{4}$ Department of Neurology, Faculty of Medical Sciences, Lebanese University, Beirut, Lebanon

${ }^{5}$ Department of Psychiatry, College of Medicine \& McKnight Brain Institute, University of Florida, Gainesville, Florida, USA

${ }^{6}$ Department of Biochemistry and Molecular Genetics, American University of Beirut Medical Center, Beirut, Lebanon

${ }^{7}$ Department of Neurosurgery, Faculty of Medical Sciences, Lebanese University, Beirut, Lebanon

Contributors JF and YF designed the study, collected the data, carried out the statistical analyses and drafted the manuscript. All authors contributed to the analysis of the results. All authors critically revised the manuscript for important intellectual content. YF is the primary investigator and guarantor of the study.

Funding This research received no specific grant from any funding agency in the public, commercial or not-for-profit sectors.

Competing interests None declared.
Ethics approval The study was approved by the Institutional Review Board at the Faculty of Medical Sciences, Lebanese University.

Provenance and peer review Not commissioned; externally peer reviewed.

Data sharing statement No additional data are available.

Open Access This is an Open Access article distributed in accordance with the Creative Commons Attribution Non Commercial (CC BY-NC 4.0) license, which permits others to distribute, remix, adapt, build upon this work noncommercially, and license their derivative works on different terms, provided the original work is properly cited and the use is non-commercial. See: http:// creativecommons.org/licenses/by-nc/4.0/

\section{REFERENCES}

1. Pietrangelo A, Higuera V. Multiple Sclerosis by the Numbers: Facts, Statistics, and You. Healthline 2015. http://www.healthline.com/ health/multiple-sclerosis/facts-statistics-infographic

2. Douglass LH, Jorgensen CL. Pregnancy and multiple sclerosis. Obstet Gynecol Surv 1948;3:797-8.

3. Tillman AJ. The effect of pregnancy on multiple sclerosis and its management. Res Publ Assoc Res Nerv Ment Dis 1950;28:548-82.

4. Sweeney WJ. Pregnancy and multiple sclerosis. Clin Obstet Gynecol 1958;1:137-48.

5. Hutchinson M. Pregnancy in multiple sclerosis. J Neurol Neurosurg Psychiatr 1993;56:1043-5.

6. Sadovnick A. Pregnancy and multiple sclerosis. Arch Neurol 1994;51:1120.

7. Rudick R. Pregnancy and multiple sclerosis. Arch Neurol 1995;52:849-50.

8. Korn-Lubetzki I, Kahana E, Cooper G, et al. Activity of multiple sclerosis during pregnancy and puerperium. Ann Neurol 1984:16:229-31.

9. Vukusic S, Marignier R. Multiple sclerosis and pregnancy in the 'treatment era'. Nat Rev Neurol 2015;11:280-9.

10. Confavreux C, Hutchinson M, Hours MM, et al. Rate of pregnancy-related relapse in multiple sclerosis. Pregnancy in Multiple Sclerosis Group. N Engl J Med 1998;339:285-91.

11. Lee M, O'Brien P. Pregnancy and multiple sclerosis. J Neurol Neurosurg Psychiatr 2008;79:1308-11.

12. O'Connor PW, Goodman A, Kappos L, et al. Disease activity return during natalizumab treatment interruption in patients with multiple sclerosis. Neurology 2011;76:1858-65.

13. Killestein J, Vennegoor A, Strijbis EM, et al. Natalizumab drug holiday in multiple sclerosis: poorly tolerated. Ann Neurol 2010;68:392-5.

14. Polman $\mathrm{CH}$, Reingold SC, Banwell $\mathrm{B}$, et al. Diagnostic criteria for multiple sclerosis: 2010 revisions to the McDonald criteria. Ann Neurol 2011;69:292-302.

15. Vukusic S, Hutchinson M, Hours M, et al. Pregnancy and multiple sclerosis (the PRIMS study): clinical predictors of post-partum relapse. Brain 2004;127:1353-60.

16. Fernández Liguori N, Klajn D, Acion L, et al. Epidemiological characteristics of pregnancy, delivery, and birth outcome in women with multiple sclerosis in Argentina (EMEMAR study). Mult Scler 2009;15:555-62.

17. Jalkanen A, Alanen A, Airas L. Pregnancy outcome in women with multiple sclerosis: results from a prospective nationwide study in Finland. Mult Scler 2010;16:950-5.

18. Salemi G, Callari G, Gammino M, et al. The relapse rate of multiple sclerosis changes during pregnancy: a cohort study. Acta Neurol Scand 2004;110:23-6.

19. Fragoso $\mathrm{Y}$, Finkelsztejn $\mathrm{A}$, Comini-Frota $\mathrm{E}$, et al. Pregnancy and multiple sclerosis: the initial results from a Brazilian database. Arq Neuro-Psiquiatr 2009;67:657-60.

20. Jacobs LD, Cookfair DL, Rudick RA, et al. Intramuscular interferon beta-1a for disease progression in relapsing multiple sclerosis. The Multiple Sclerosis Collaborative Research Group (MSCRG) Ann Neurol 1996;39:285-94.

21. van Walderveen MA, Tas MW, Barkhof $F$, et al. Magnetic resonance evaluation of disease activity during pregnancy in multiple sclerosis. Neurology 1994;44:327-9.

22. Sandberg-Wollheim M, Frank D, Goodwin TM, et al. Pregnancy outcomes during treatment with interferon beta-1a in patients with multiple sclerosis. Neurology 2005;65:802-6.

23. Boskovic R, Wide $\mathrm{R}$, Wolpin $\mathrm{J}$, et al. The reproductive effects of beta interferon therapy in pregnancy: a longitudinal cohort. Neurology 2005;65:807-11. 
24. Dwosh E, Guimond C, Sadovnik AD. Reproductive counseling in MS: a guide for healthcare professionals. Int MS J 2003; $10: 67$.

25. Coyle $\mathrm{P}$, Johnson $\mathrm{K}$, Padro L, et al. Pregnancy outcomes in patients with multiple sclerosis treated with glatiramer acetate (Copaxone). Neurology 2003;60:A60.

26. De Las Heras $\mathrm{V}$, De Andrés $\mathrm{C}$, Téllez $\mathrm{N}$, et al. Pregnancy in multiple sclerosis patients treated with immunomodulators prior to or during part of the pregnancy: a descriptive study in the Spanish population. Mult Scler 2007;13:981-4.

27. Hellwig K, Brune N, Haghikia A, et al. Reproductive counselling, treatment and course of pregnancy in 73 German MS patients. Acta Neurol Scand 2008;118:24-8.

28. Sandberg-Wollheim M, Alteri E, Moraga MS, et al. Pregnancy outcomes in multiple sclerosis following subcutaneous interferon beta-1a therapy. Mult Scler 2011;17:423-30.

29. Jalkanen A, Kauko T, Turpeinen U, et al. Multiple sclerosis and vitamin D during pregnancy and lactation. Acta Neurol Scand 2015;131:64-7.

30. Lips $\mathrm{P}$, Hosking $\mathrm{D}$, Lippuner $\mathrm{K}$, et al. The prevalence of vitamin $D$ inadequacy amongst women with osteoporosis: an international epidemiological investigation. J Intern Med 2006;260:245-54

31. Etemadifar M, Janghorbani M. Efficacy of high-dose vitamin D3 supplementation in vitamin $\mathrm{D}$ deficient pregnant women with multiple sclerosis: preliminary findings of a randomized-controlled trial. Iran $J$ Neurol 2015;14:67-73.

32. Ayoub F, Fares $\mathrm{Y}$, Fares J. The psychological attitude of patients toward health practitioners in Lebanon. $N \mathrm{Am} J \mathrm{Med} S \mathrm{Sci}$ 2015;7:452-8.

33. Ueda A, Kondoh E, Kawasaki K, et al. Magnesium sulphate can prolong pregnancy in patients with severe early-onset preeclampsia. $J$ Matern Fetal Neonatal Med 2015. doi:10.3109/14767058. 2015.1114091
34. Giannubilo SR, Tiano L, Ciavattini A, et al. Amniotic coenzyme q10: is it related to pregnancy outcomes? Antioxid Redox Signal 2014;21:1582-6.

35. Bentov Y, Casper RF. The aging oocyte-can mitochondrial function be improved? Fertil Steril 2013;99:18-22.

36. Bentov $\mathrm{Y}$, Esfandiari N, Burstein E, et al. The use of mitochondrial nutrients to improve the outcome of infertility treatment in older patients. Fertil Steril 2010;93:272-5.

37. Dahl J, Myhr KM, Daltveit AK, et al. Pregnancy, delivery, and birth outcome in women with multiple sclerosis. Neurology 2005;65:1961-3.

38. Pastò L, Portaccio E, Ghezzi A, et al. Epidural analgesia and cesarean delivery in multiple sclerosis post-partum relapses: the Italian cohort study. BMC Neurol 2012;12:165.

39. Miller DH, Fazekas F, Montalban X, et al. Pregnancy, sex and hormonal factors in multiple sclerosis. Mult Scler 2014;20:527-36.

40. Portaccio E, Ghezzi A, Hakiki B, et al. Breastfeeding is not related to postpartum relapses in multiple sclerosis. Neurology 2011;77:145-50.

41. Langer-Gould A, Huang SM, Gupta R. Exclusive breastfeeding and the risk of postpartum relapses in women with multiple sclerosis. Arch Neurol 2009;66:958-63.

42. Hellwig K, Haghikia A, Rockhoff $M$, et al. Multiple sclerosis and pregnancy: experience from a nationwide database in Germany. Ther Adv Neurol Disord 2012;5:247-53.

43. Hughes SE, Spelman T, Gray OM, et al. Predictors and dynamics of postpartum relapses in women with multiple sclerosis. Mult Scler 2014;20:739-46.

44. Saraste MH, Kurki T, Airas LM. Postpartum activation of multiple sclerosis: MRI imaging and immunological characterization of a case. Eur J Neurol 2006;13:98-9.

45. Paavilainen T, Kurki T, Parkkola R, et al. Magnetic resonance imaging of the brain used to detect early post-partum activation of multiple sclerosis. Eur J Neurol 2007;14:1216-21. 